\title{
Human myiasis survey in Ilam Province, Southwest of Iran
}

\author{
MORTEZA AKBARI ${ }^{1}$, JAVAD RAFINEJAD ${ }^{1}$, AHMAD-ALI HANAFI-BOJD ${ }^{1}$, ALI ASHRAF AIVAZI ${ }^{2}$, \\ AKBAR BIGLARIAN ${ }^{3}$, SORAYA SHEIKHI ${ }^{1}$, ZAHRA SHAVALI ${ }^{1}$, KAMRAN AKBARZADEH $^{1, \bullet}$ \\ ${ }^{1}$ Department of Medical Entomology \& Vector Control, School of Public Health and National Institute of Health Research, Tehran University of Medical \\ Sciences. Tehran, Iran. `email: kamran.akbarzadeh@yahoo.com, akbari.morteza1@yahoo.com \\ ${ }^{2}$ Department of Public Health, School of Health, Ilam University of Medical Sciences. Ilam, Iran \\ ${ }^{3}$ Department of Biostatistics, University of Social Welfare and Rehabilitation Sciences. Tehran, Iran
}

Manuscript received: 5 October 2020. Revision accepted: 19 October 2020.

\begin{abstract}
Akbari M, Rafinejad J, Hanafi-Bojd AA, Aivazi AA, Biglarian A, Sheikhi S, Shavali Z, Akbarzadeh K. 2020. Human myiasis survey in Ilam Province, Southwest of Iran. Nusantara Bioscience 12: 143-147. Myiasis is the infestation of live human and vertebrate animals with dipterous larvae, which at least for a period. Ilam Province of Iran is one of the most important animal husbandry areas, especially nomadic, in Iran. The objective of this study was to identify the prevalence of myiasis in shepherds in Ilam Province. A crosssectional study was conducted among the shepherds in Ilam Province, western Iran. Out of the 11 counties in Ilam Province, 6 were randomly chosen from three different climates for this study. A questionnaire was used by a trained interviewer to obtain the information from subjects. The disease has been seen in spring, summer, and autumn seasons. About $94.1 \%$ of people have been infested at least once. Pharyngeal myiasis had the highest prevalence with 58.3\%. Itchy, painful throat, sneeze, cough, and headache were common symptoms. About $85.1 \%$ of people described the symptoms of the disease as severe and very severe. About $75.4 \%$ stated that the duration of the disease was more than 5 days. According to the results of the study, it was found that the prevalence of myiasis among shepherds in the Ilam Province is high and it is necessary to take appropriate measures to control the disease and increase health literacy.
\end{abstract}

Keywords: Flies, Iran, myiasis, surveys

\section{INTRODUCTION}

Non-biting flies may be medically important because of direct damage to the human or animal by attacking with the larval stage (more commonly known as maggots). Myiasis is defined as the infestation of tissues and organs of living or dead human and vertebrate, for a period due to the dipterous larvae invasion, feed on the host's dead or living tissue, liquid body substances, or ingested food (Ramana 2012). It can lead to severe injury, secondary infection, prolonged pain, tissue, and fluid loss, reduced fitness, and even death, especially if sensitive organs such as the nose, eyes, and ears are attacked by larvae (Ramana 2012).

Myiasis has been defined by Zumpt and has been reported in various world regions (Smith 1973). It remains a neglected disease (Otranto and Stevens 2002), and in the vast majority of cases a self-limiting infection with minimal complications (McGraw and Turiansky 2008). The disease is more prevalent in areas where many people are engaged in animal husbandry. Myiasis is a common medical and veterinary problem in many tropic areas (Baskaran et al. 2007). Myiasis is considered an occupational disease among people who live near the livestock and affects mainly persons in rural areas such as butchers, shepherds, and farmers (Masoudi and Hosseini 2004).

In the entomological method, myiasis classifies according to the type of host-parasite relationship. In this way, myiasis is divided into facultative, obligatory, and accidental forms (Ward 2008). Species of the fly are involved, and most vertebrate animals are susceptible to this disease. Although humans can suffer from myiasis, it is much more common in livestock and wildlife, and flies, especially in the obligatory form. The first report of myiasis in Iran, an ophthalmomyiasis in a woman in Tehran, was reported in1976 by Minar (Minar 1976) and up to 2017 , about 81 cases of human myiasis have been reported (Hazratian et al. 2020).

Human and animal myiasis is not defined in Iranian health and veterinary reporting systems (Alizadeh et al. 2014). Therefore the epidemiology of this disease in some parts of Iran is unclear but according to previous studies, the prevalence of the disease among shepherds and cattle breeders has been reported as very high (Salimi et al. 2010). Losses in livestock due to myiasis have been substantial. There have been $\$ 800$ million in losses annually to cattlemen from the southern USA from Florida to California (Eldridge and Edman 2012). Although such an estimate has not been reported in Iran, the great economic damage caused by myiasis among domestic animals and disease in humans is apprehended posing to be a major threat to the livestock industry and the health system in Iran (Shoorijeh et al. 2011). More than $6,400 \mathrm{~km}^{2}$ of the Ilam Province, about $31 \%$ of its territory, is covered with scattered to dense forests. Due to its geographical location, natural conditions, and the diversity of its habitats, Ilam Province is one of the most important animal husbandry areas, especially nomadic, in Iran. Based on the 
statistics, more than $50 \%$ of the province's employment depends on livestock and animal husbandry. Although it seems the myiasis disease has been highly prevalent in humans and animals in Ilam Province, to our best knowledge, it has not been studied yet. Thus, the objective of this study was to identify the prevalence of myiasis in shepherds in Ilam Province. Current data on this disease can be helpful in the prevention, diagnosis, cure, and surveillance of health programs.

\section{MATERIALS AND METHODS}

\section{The study area}

Ilam Province is located in the western part of Iran, between $32^{\circ} 03^{\prime}$ and $34^{\circ} 02^{\prime}$ North longitude and $45^{\circ} 40^{\prime}$ and $48^{\circ} 03^{\prime}$ East latitude. It has an area of $20,150 \mathrm{~km}^{2}$ and sharing $425 \mathrm{~km}$ of border with Iraq, and also bordering on the provinces of Kermanshah, Lorestan, and Khuzestan. The province consists of 11 counties and its capital is Ilam city (Fig 1). Due to various factors such as altitude, proximity to the Arabian Desert, the plains of Khuzestan, and Iraq, the climate of the province is so diverse: Northern mountainous areas such as Ilam and Eyvan have temperate climates, cold winters and mild summers with an annual rainfall of about $600 \mathrm{~mm}$. While the southern and southwestern plains such as Mehran and Dehloran have a very hot climate with an annual rainfall of about $200 \mathrm{~mm}$.
The rest of the province is experiencing something between these two climates.

\section{Study procedure}

A cross-sectional study was conducted among the shepherds in Ilam Province from April to June 2020. Out of the 11 counties in Ilam Province, 6 were randomly selected from three different climates for this study as follows: Ilam and Eyvan in the northern part, Abdanan and Darreh Shahr in the central part, and Dehloran and Mehran in the southern part of the province. The interview tool was a questionnaire. To determine the reliability of the questions in each domain, the validity of the questionnaire was examined using Cronbach's alpha index. For Cronbach's alpha, questions were considered reliable if values of 0.7 and above 0.7 were found.

\section{Statistical analysis}

The sample size (n) $=Z 1-\alpha / 2 \quad \mathrm{pq} / \mathrm{d} 2=268$ was calculated where $\mathrm{p}=0.775$ (4), $\mathrm{q}=0.225, \mathrm{~d}=0.05$ at $95 \%$ confidence and 5\% level of significance. A researchermade questionnaire on human myiasis was used by a trained interviewer to obtain information from subjects. The data were analyzed using SPSS version 22 software.

\section{Species identification}

The identification of flies was performed using valid and identification keys (Smith 1989).

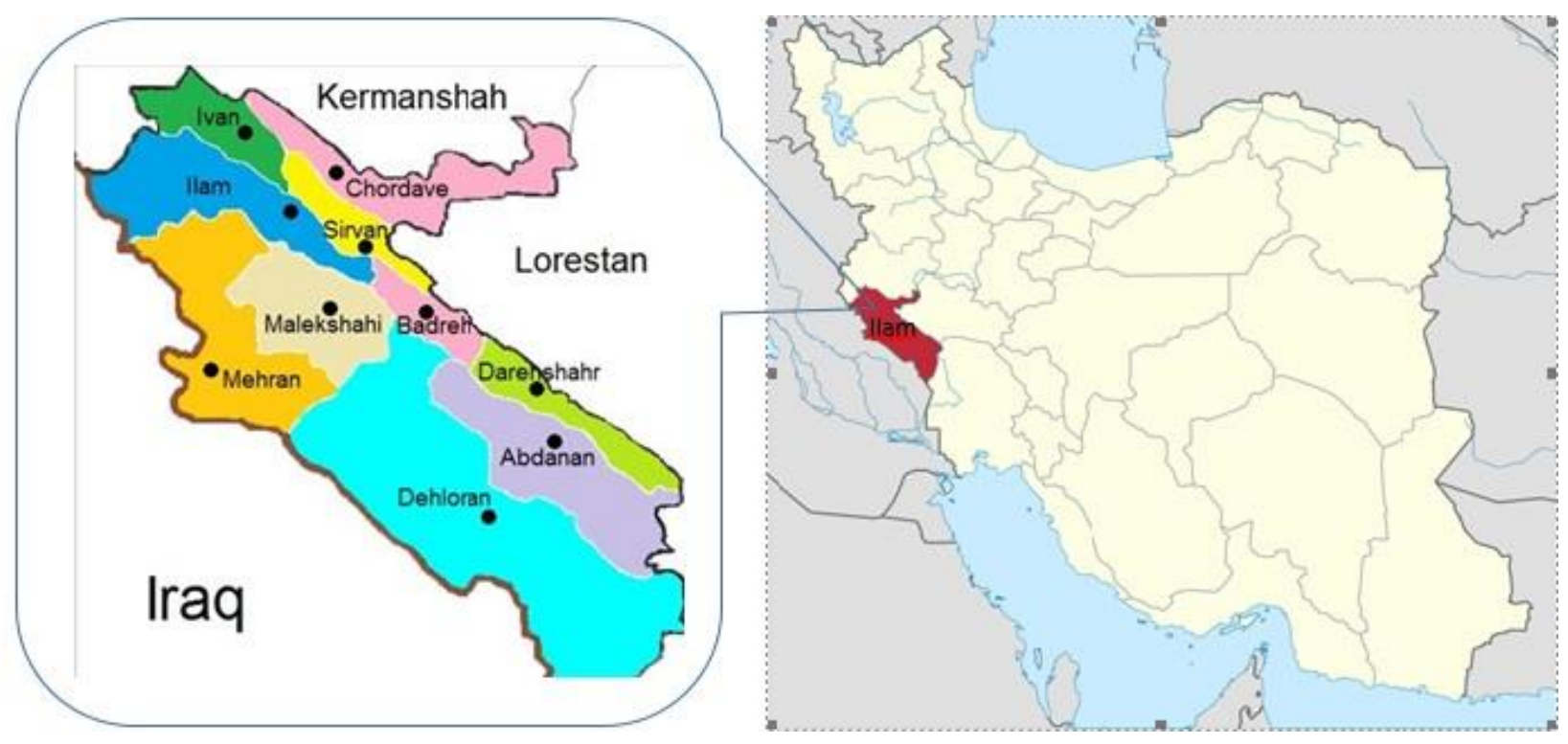

Figure 1. The geographical location of Ilam Province, southwest of Iran 


\section{RESULTS AND DISCUSSION}

The present study was conducted among 290 shepherds in the selected county of Ilam Province in the west of Iran. In each household, one person responded to the questionnaire. Out of them, $49 \%$ was the head of the family, $23.4 \%$ the spouse, and $28.6 \%$ the children. $61 \%$ of participants were male and $39 \%$ were female.

The results showed that the myiasis has been seen in spring, summer, and autumn seasons. It was most prevalent in summer with $63.4 \%$ of self-declaration. About $93.8 \%$ of people were breeding sheep, and $72.4 \%$ reported their family members' infestation history. About $94.1 \%$ of people have been infected at least once and $11 \%$ have experienced it more than 10 times (Table 1). About $43.8 \%$ believed that they got the disease while grazing, $22.1 \%$ got the disease while resting next to the animals, and $34.1 \%$ got the disease while keeping the animals. Pharyngeal myiasis showed the highest prevalence with $58.3 \%$ compared to other places (Table 2).

Itching, fever, sore throat, sneezing, cough, watery eyes, and headache were common symptoms reported by participants, with cough being the most common (\%64.5) (Table 3). About $85.1 \%$ of people described the symptoms of the disease as severe and too severe (Figure 2).

About $75.4 \%$ stated that the duration of the disease was more than 5 days. Regarding the participants' literacy, $31.7 \%, 22.8 \%, 12.8 \%, 17.9 \%, 6.2 \%$, and $8.5 \%$ of studied subjects were illiterate, primary school, middle school, high school, an associate, and Bachelor degree, respectively.

The job experience varied from 2 to 67 years: $9.7 \%$ had $<5$ years, $26.9 \%$ had $6-15$ years, $24.8 \%$ had $16-25$ years, $13.1 \%$ had $26-35$ years, $8.6 \%$ had $36-45$ years and $16.9 \%$ had $>46$ years work experience. Fifty-seven-point eight percent of subjects had a nomadic life, while $42.8 \%$ lived in rural areas.

Myiasis is a serious problem in animal production and commonly found among domestic animals in tropical regions and is one of the health problems of worldwide occurrence particularly in animal raising countries like Iran. Clinically, myiasis can be classified based on The part of the host's body that is infested (Bennett et al. 2014). In this study, it was found that the most type of myiasis was pharyngeal myiasis $(58.3 \%)$. All parasitological types of myiasis have been reported from Iran (Alizadeh et al. 2014).

Agents of the most reported cases of myiasis in Iran belong to three families of flies, Calliphoridae, Sarcophagidae, and Oestridae. Many species of Diptera that cause myiasis are not yet identified in Iran. (Hazratian et al. 2020).

Due to climatic conditions, Ilam Province, have been engaged in animal husbandry since ancient times and is considered as one of the centers of livestock production in Iran. This study was performed on shepherds who are of the most important at-risk groups of this disease. Due to closely related activity of myiasis agents with livestock, the prevalence of myiasis in this province is very high, and during the activity season of myiasis-causing flies, a high percentage of shepherds suffered from this disease. The result of the present study also showed that the prevalence of this disease is very high among shepherds and $94.1 \%$ of participants had the disease at least once. In a questionnaire-based study conducted in Fars province cleared that more than $88 \%$ of the participants were infected at least one time with myiasis (Akbarzadeh et al. 2012).

Based on the statements of the participants in the study about the behavior of flies, it seems that the predominant cause of the disease in this area is Oestrus ovis. Some of the cattle herders caught the attacking flies, which were $O$. ovis. Infection by the larvae of $O$. ovis was reported in other parts of Iran and is a well-known zoonosis. (Akbarzadeh et al. 2012a, 2018; Nateghpour and Akbarzadeh 2017).

Table 1. Prevalence of myiasis infestation in shepherds according to the history of infection in Ilam, southwest of Iran

\begin{tabular}{lccc}
\hline $\begin{array}{c}\text { History of } \\
\text { infection }\end{array}$ & Frequency & Percent & $\begin{array}{c}\text { Cumulative } \\
\text { percent }\end{array}$ \\
\hline 0 & 17 & 5.9 & 5.9 \\
1 & 104 & 35.9 & 41.7 \\
$2-5$ & 107 & 36.9 & 78.6 \\
$6-10$ & 30 & 10.3 & 89.0 \\
$>10$ & 32 & 11.0 & 100.0 \\
Total & 290 & 100.0 & \\
\hline
\end{tabular}

Table 2. Prevalence of myiasis infestation in shepherds according to types of myiasis in Ilam, southwest of Iran

\begin{tabular}{lcc}
\hline Type of myiasis & Frequency & Percent \\
\hline Eye & 57 & 19.7 \\
Pharynx & 169 & 58.3 \\
Nose & 78 & 26.9 \\
Ear & 37 & 12.8 \\
More than one place & 124 & 42.8 \\
\hline
\end{tabular}

Table 3. Frequency of myiasis clinical symptoms reported in Ilam, southwest of Iran

\begin{tabular}{lcc}
\hline Clinical symptoms & Frequency & Percent \\
\hline Itching & 107 & 36.9 \\
Sore throat & 181 & 62.4 \\
Watery eyes & 169 & 58.3 \\
Headache & 82 & 28.3 \\
Fever & 69 & 23.8 \\
Sneezing & 163 & 56.2 \\
Cough & 187 & 64.5 \\
Chills & 16 & 5.5 \\
\hline
\end{tabular}




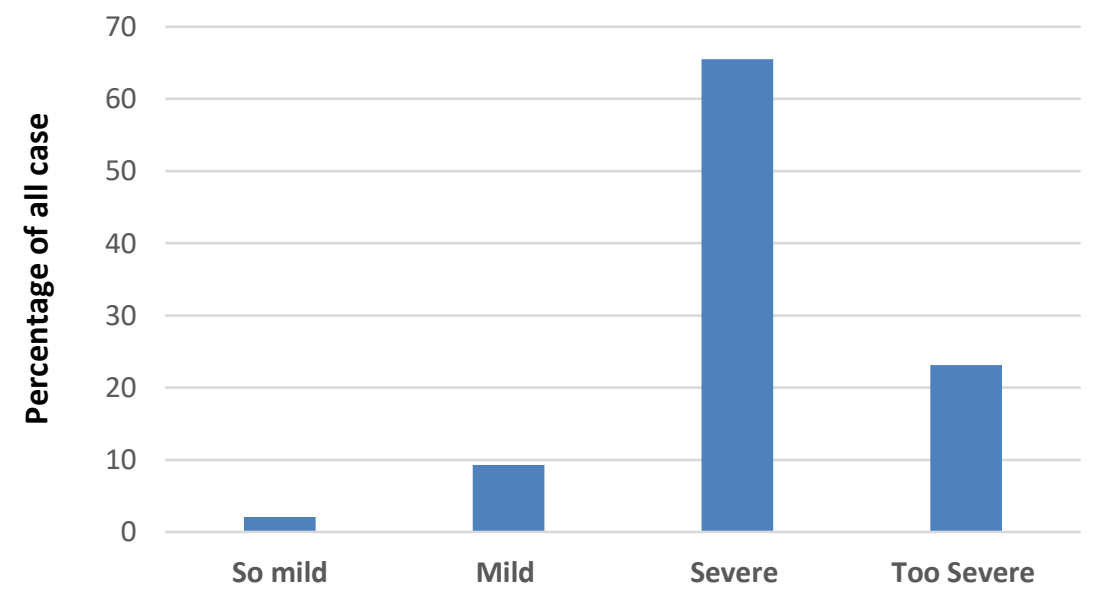

Figure 2. Percent of disease severity in Ilam, southwest of Iran

The total number of cases of myiasis in all documents published in Iran was 81 (Hazratian et al. 2020). Based on clinical/descriptive features, it was found that the majority of cases $(52 \%)$ were oral myiasis. Oestrus ovis is commonly known as the cause of oral myiasis. About $65 \%$ of the reported cases in Iran were produced by this species. It can be concluded that this fly can be mentioned as a cause of human myiasis in the country (Alizadeh et al. 2014; Hazratian et al. 2017). Based on the results of this study and other similar studies, it has been determined that a large number of people at risk are involved with this disease, so it was found that the total number of cases of oral myiasis in Iran is more than 40 reported in the literature. Oestrus ovis is an obligate parasite of sheep and goats, and the causative agent of oestrosis, leads to severe clinical manifestations in livestock +and human. The $O$. ovis larva is a typical parasite of the pharynx, ears, nose, eyes, and skin of sheep and goats and sometimes humans (Dunbar et al. 2008). Also in Fars province, the causative agent of myiasis was reported as $O$. ovis (Akbarzadeh et al. 2012). In this study $93.4 \%$ of the shepherds had sheep and $83.1 \%$ had goats. Sheep and goats are the main hosts of $O$. ovis (Ahaduzzaman 2019). In a study conducted in Kashan, the rate of infection in goats was $3.2 \%$ and in sheep was $2.3 \%$ (Dehghani et al.2012). In another study conducted in Shiraz to determine the infection of goats with $O$. ovis, $13.1 \%$ of livestock Infected and the most contamination was seen in winter and the least contamination was seen in spring that this may be because the larvae overwinter in the sinuses or around the nasal passages (Shoorijeh et al. 2011). However, in a study conducted in Urmia on the infection of sheep with $O$. ovis, $30.34 \%$ of the animals were infected and the most infection was seen in autumn (Tavassoli et al. 2012). More than $62 \%$ of all myiasis reports were in Fars province. This may be due to comprehensive studies in active search of the disease and its causes (Akbarzadeh et al. 2012a,b).

Very few studies have been performed on the status of myiasis in humans in Iran, and it is necessary to conduct similar studies in areas where the prevalence of the disease is thought to be high to the identification of myiasisproducing Diptera fauna in Iran. It provides useful information to health policymakers to make the right policies. Simultaneous studies in different regions of Iran may change the geographical distribution of myiasis in Iran.

The results of this research provide useful information about human myiasis in Ilam Province. Myiasis is a major medical and veterinary concern, especially in areas where animal husbandry is common. At the same time, it is of great medical importance in a region such as Ilam Province, where the economic situation of a large part of the population depends on the livestock industry. Parasites are highly mobile and clinical signs are variable.

\section{ACKNOWLEDGMENTS}

The authors would like to appreciate the efforts of Miss. Aghaeiyan. We would like to thank the Ilam University of Medical Sciences, Iran for their kindly cooperation. This study was part of a PhD dissertation of MA funded and supported by Tehran University of Medical Sciences, Tehran, Iran (Grant no. 9421260005).

\section{REFERENCES}

Ahaduzzaman M. 2019. The global and regional prevalence of oestrosis in sheep and goats: a systematic review of articles and meta-analysis. Parasites Vectors 12 (1), 346.

Akbarzadeh K, Rafinejad J, Alipour H, Biglarian A. 2012a. Human myiasis in Fars province, Iran. Southeast Asian J Trop Med Publ Health 43 (5): 1205-1211.

Akbarzadeh K, Rafinejad J, Nozari J, Rassi Y, Sedaghat MM, Hosseini M. 2012b. A modified trap for adult sampling of medically important flies (Insecta: Diptera). J Arthropod-borne Dis 6 (2): 119-128.

Akbarzadeh K, Saghafipour A, Jesri N, Karami-Jooshin M, Arzamani K, Hazratian T, Kordshouli RS, Afshar AA. 2018. Spatial distribution of necrophagous flies of infraorder muscomorpha in Iran using geographical information system. J Med Entomol 55 (5): 1071-1085. 
Alizadeh M, Mowlavi G, Kargar F, Nateghpour M, Akbarzadeh K, Hajenorouzali-Tehrani M. 2014. A review of myiasis in Iran and a new nosocomial case from Tehran, Iran. J Arthropod-Borne Dis 8 (2): 124-131.

Baskaran M, Kumar BJ, Geeverghese A. 2007. Cutaneous myiasis of face. J Oral Maxillofac Pathol 11 (2), 70.

Bennett JE, Dolin R, Blaser MJ. 2014. Mandell, Douglas, and Bennett's Principles and Practice of Infectious Diseases. Elsevier Health Sciences.

Dehghani R, Sedaghat MM, Esmaeli N, Ghasemi A. 2012. Myiasis among slaughtered animals in Kashan, Iran: descriptive a veterinary entomological problem in the tropics. Iran J Vet Sci Technol 4 (1): 19-28.

Dunbar J, Cooper B, Hodgetts T, Yskandar H, van Thiel P, Whelan S, Taylor J Woods DR. 2008. An outbreak of human external ophthalmomyiasis due to Oestrus ovis in Southern Afghanistan. Clin Infect Dis 46 (11): e124-e126. https://doi.org/10.1086/588046

Eldridge BF, Edman JD. 2012. Medical Entomology: A Textbook on Public Health and Veterinary Problems caused by Arthropods. Springer Science \& Business Media.

Hazratian T, Dolatkhah A, Akbarzadeh K, Khosravi M, Ghasemikhah R. 2020. A review of human myiasis in Iran with an emphasis on reported cases.

Hazratian T, Tagizadeh A, Chaichi M, Abbasi M. 2017. Pharyngeal myiasis caused by sheep botfly, Oestrus ovis (Diptera: Oestridae) larva, Tabriz, East Azarbaijan Province, Iran: a case report. J Arthropod-Borne Dis 11 (1): 166-170.

Jafari SS, Jola GM. 2001. Efficacy of ivermectin against Oestrus ovis in sheep. Sci J Sch Vet Med 6, 16-29.
Masoudi M, Hosseini K. 2004. External ophthalmomyiasis caused by sheep botfly (Oestrus ovis) larva: A report of 8 cases. 7 (2): 136-136.

McGraw TA, Turiansky GW. 2008. Cutaneous myiasis. J Am Acad Dermatol 58 (6): 907-926.

Minar J. 1976. A case of eye myiasis in man caused by first instar larvae of Oestrus ovis L. (Diptera, Oestridae) in Iran. Folia Parasitol 23 (3): 283-284.

Nateghpour M, Akbarzadeh K. 2017. Necrophagous flies of synanthropic habitats in South-East Iran. Orient Insects 51 (4): 380-390.

Otranto D, Stevens JR. 2002. Molecular approaches to the study of myiasis-causing larvae. Int J Parasitol 32 (11): 1345-1360.

Ramana K. 2012. Human myiasis. J Med Microbiol Diagn 1 (2): e105. doi:10.4172/2161-0703.1000e105

Salimi M, Edalat H, Jourabchi A, Oshaghi M. 2010. First report of human nasal myiasis caused by Eristalis tenax in Iran (Diptera: Syrphidae). Iran J Arthropod-Borne Dis 4 (1): 77-80.

Shoorijeh JS, Tamadon A, Negahban S, Behzadi M. 2011. Prevalence of Oestrus ovis in goats of Shiraz, southern Iran. Vet Arh 81 (1): 43-49.

Smith KG. 1973. Insects and other arthropods of medical importance. Insects and other arthropods of medical importance.

Smith KG. 1989. An introduction to the immature stages of British flies: Diptera larvae, with notes on eggs, puparia, and pupae. Royal Entomological Society 10 (14).

Tavassoli M, Tajik H, Malekifard F, Soleimanzadeh A, Mardani K. 2012. Seasonal infestation of Oestrus ovis larvae in slaughtered sheep in Urmia, Iran (short paper). Sci-Res Iran Vet J 7 (4): 73-78.

Ward RD. 2008. Service MW: Medical Entomology for Students. Cambridge University Press, UK. 